quiescent for 18 months. Her drug treatment consisted of oral mesalazine $800 \mathrm{mg}$ twice daily, which she had been taking for the past eight months. She had previously taken sulphasalazine for several years but had stopped this after developing arthralgia.

On examination there was decreased air entry at both lung bases and no other abnormality. Investigations showed a white cell count of $11.3 \times 10^{9} / 1$ with $16 \%$ eosinophils and a high plasma viscosity; she was negative for rheumatoid factor, weakly positive for antinuclear factor, and strongly positive for antibody to neutrophil cytoplasm (titre $1 / 400$ ). The pattern of staining of the antibody to neutrophil cytoplasm was cytoplasmic, and the neutrophils were negative for antibodies to myeloperoxidase, lactoferrin, and cathepsin G. Initial urine testing showed microscopic haematuria, an isotope lung scan did not show any abnormality, and an electrocardiogram was normal. She was unable to perform lung function tests because of coughing. A chest $x$ ray film showed bilateral lung infiltrates, especially at the apexes, and bilateral small pleural effusions.

In view of the picture of pulmonary eosinophilia, haematuria, and strongly positive titre of antibodies to neutrophil cytoplasm a thoracoscopic lung biopsy specimen was taken from the right upper lobe. It showed no evidence of Wegener's granulomatosis or pneumonia due to bronchiolitis obliterans: appearances were those of a chronic eosinophilic pneumonia. Mesalazine was stopped, and the patient refused steroid treatment. Her condition improved over the next few weeks, and the abnormalities in the chest $x$ ray film and blood eosinophilia resolved. The titre of antibody to neutrophil cytoplasm was still $1 / 400$ three weeks after she stopped taking mesalazine but had fallen to $1 / 25$ a few months later.

This patient's illness was probably caused by mesalazine. Pulmonary side effects from this drug are rare and may occur soon after the drug is started, as in the case described by Lim and Hine, or after many months of exposure, ${ }^{2}$ as in this case. One report mentions a strongly positive titre of antinuclear anbitody, which fell after mesalazine was stopped. ${ }^{3}$ Ulcerative colitis may cause a positive result in a test for antibodies to neutrophil cytoplasm, but the staining is usually perinuclear. ${ }^{4}$ The high titre of antibody to neutrophil cytoplasm with a cytoplasmic staining pattern, which fell when mesalazine was stopped, raises the possibility of a link with the drug.

Department of Thoracic Medicine,

D HONEYBOURNE

Birmingham B187QH

$1 \mathrm{Lim}$ AG, Hine KR. Fever vasculitic rash, arthritis, pericarditis, and pericardial effusion after mesalazine. BMf 1994;308:113. (8 January.)

2 Reinoso MA, Schroeder KW, Pisani RJ. Lung disease associated with orally administered mesalazine for ulcerative colitis. Chest 1992;101:1469-71.

3 Welte T, Hamm H, Fabel H. Mesalazine alveolitis. Lancet 1991;338:1273.

4 Cambridge G, Rampton DS, Stevens TRJ, McCarthy DA, Kamm M, Leaker B. Anti-neutrophil antibodies in inflammatory bowel disease: prevalence and diagnostic role. Gut 1992;33:668-74.

\section{Safety of tamoxifen}

EdrToR,-V Craig Jordan reports some of the preclinical toxicological findings on tamoxifen in his editorial. ${ }^{1}$ Though he states that tamoxifen "promotes hepatic tumours in rats," he fails to note that tamoxifen is a strong liver carcinogen by itself in rats, producing tumours within six months and a high incidence by one year at doses that yield blood concentrations comparable to those in treated women. ${ }^{2}$ In addition to causing the formation of DNA adducts in the liver of rats, which Jordan mentions, tamoxifen causes the formation of DNA adducts in the liver of hamsters and mice. This feature is characteristic of human carcinogens. In fact, tamoxifen is associated with increases in cancers of the endometrium ${ }^{34}$ and possibly liver ${ }^{3}$ in treated patients.

In answer to the question "Is tamoxifen safe?" Jordan compares the risk of tamoxifen with that of use of oral contraceptives on the basis of his conclusion that it is the oestrogenic properties of tamoxifen that result in the assumed, but not proved, ability of tamoxifen to promote hepatic tumours in rats. This conclusion fails to take into account other aspects of the toxicology of tamoxifen, as noted above, which are different from the effects of oestrogens. The weakness of the comparison with oestrogens is further illustrated by the fact that toremifene, which is related to tamoxifen and has comparable oestrogenic properties in liver, is not hepatocarcinogenic. $^{2}$

It is important to ascertain whether breast cancer can be prevented without the potential risks of tamoxifen being imposed. Considerable evidence supports the view that breast cancer can be substantially prevented by reduction of dietary consumption of fat, ${ }^{5}$ which entails no risk and affords other benefits. If chemical intervention is deemed necessary the antioestrogen toremifene could be used.

GARY M WILLIAMS

American

NY 10595, USA

1 Jordan VC. How safe is tamoxifen? BMf 1993;307:1371-2. (27 November.)

2 Hard GC, Iatropoulos MJ, Jordan K, Radi L, Kaltenberg O, Imondi $\mathrm{AR}$, et al. Major difference in the hepatocarcinogenicity and DNA adduct forming ability between toremifene genicity and DNA adduct forming ability between toremifene 1993;53:4534-41.

3 Fornander T, Rutqvist LE, Cedermark B, Glas V, Mattsson A Silfverswärd $\mathrm{C}$, et al. Adjuvant tamoxifen in early breas cancer: occurrence of new primary cancers. Lancet 1989;i:117 20.

4 De Muylder X, Neven P. Tamoxifen and potential adverse effects. Cancer fournal 1993;6:111-5.

5 Cohen LA, Rose DP, Wynder EL. A rationale for dietary intervention in postmenopausal breast cancer patients: an update. Nutrition and Cancer 1993;19:1-10.

\section{Genetic susceptibility to non- insulin dependent diabetes}

EDITOR,-Eva Tuomilehto-Wolf and coworkers have presented the interesting hypothesis that genetic susceptibility to non-insulin dependent diabetes mellitus is located in the HLA region. Their conclusions are based on findings in 157 elderly Finnish men (age 70-89), in whom HLA haplotypes associated with insulin dependent diabetes could explain $98 \%$ of non-insulin dependent diabetes and $79 \%$ of impaired glucose tolerance. This association depended strongly on the presence of HLA-DR4, which was observed in 57\% (56/98) of patients with non-insulin dependent diabetes but only $13 \%(3 / 23)$ of controls $(\mathrm{P}=$ 0.003 ). The frequency of HLA-DR4 in the patients with non-insulin dependent diabetes is in the same range as that previously reported from Finland $^{2}$ and the United States ${ }^{3}$ (table). The frequency in the control population is considerably lower than that previously reported, but this is most probably due to the small number of control subjects studied.

Prevalence of $H L A-D R 4$ in patients with non-insulin dependent diabetes. Figures are numbers (percentages) of patients

\begin{tabular}{lccc}
\hline Study & Controls & $\begin{array}{c}\text { Non-insulin } \\
\text { dependent } \\
\text { diabetes }\end{array}$ & P value \\
\hline Groop et a $^{2}$ & $86 / 322(28)$ & $51 / 121(51)$ & 0.02 \\
Rich et a $^{3}$ & $62 / 221(27)$ & $36 / 86(42)$ & 0.02 \\
Tuomilehto-Wolf et al & $3 / 23(13)$ & $56 / 98(57)$ & 0.03 \\
\hline
\end{tabular}

If patients with non-insulin dependent diabetes are divided into insulin requiring and non-insulin requiring on the basis of a glucagon stimulated C peptide concentration $<0.6 \mathrm{nmol} / 1$, however, only the insulin requiring patients show an increased frequency of HLA-DR4 (54\% (37/69) compared with $32 \%(41 / 127)$ in patients whose condition was controlled with oral antidiabetic agents). ${ }^{4}$ Patients with DR4 had lower C peptide concentrations than patients with other HLA-DR antigens. $^{2}$

Since high insulin and $\mathrm{C}$ peptide concentrations are associated with an increased risk of cardiovascular disease we propose that these patients represented a subgroup of patients with noninsulin dependent diabetes protected against cardiovascular disease. Therefore, the increase in frequency of HLA-DR4 is due to an admixture of patients with genes conferring susceptibility to insulin dependent diabetes rather than a general feature of patients with non-insulin dependent diabetes. In the search for genes for non-insulin dependent diabetes correct definition of the phenotype is critical, since the disease is likely to be heterogenous.

LEIF GROOP

Department of Endocrinology,

University of Lund

Malmö General Hospital,

S-214 01 Malmö, Sweden

GIAN FRANCO BOTTAZZO

Department of Immunology,

London Hospital Medical College,

London E1 2AD

Tuomilehto-W/f $E$ Tuomilehto J, Hitman GA, Nissinen A, Stengasd J, Pekkanen J, et al. Genetic susceptibility to noninsulin-dependent diabetes mellitus and glucose intolerance are located in HLA region. BMf 1993;307:155-9. (17 July.)

2 Groop L, Groop P-H, Koskimies S. Relationship between B-cell function and HLA antigens in patients with type 2 (noninsulin-dependent) diabetes mellitus. Diabetologia 1986;29: 757-60.

3 Rich SS, French LR, Sprafka JM, Clements JP, Goetz FC. HLAassociated susceptibility to type 2 (non-insulin-dependent) diabetes mellitus: the Wadena City health study. Diabetologia 1993;36:234-8.

4 Groop L, Miettinen A, Groop P-H, Meri S, Koskimies S, Bottazzo GF. Organ-specific autoimmunity and HLA-DR antigens as markers for B-cell destruction in patients with type II diabetes. Diabetes 1988;37:99-103.

\section{Breast feeding and diabetes mellitus}

EDrToR,-K G M M Alberti briefly mentions that "breast feeding has been shown to protect against the development of insulin dependent diabetes mellitus." Two papers have strongly suggested that infants born into families with a family history of diabetes have a lesser chance of developing insulin dependent diabetes if they are breast fed up to the age of 9-12 months. ${ }^{23}$ This breast feeding must be exclusive of top up formula milk feeds as these initiate the autoimmune process that may result in insulin dependent diabetes in later life. This message seems not to be getting across to diabetic people in the community. Doctors, health visitors, and midwives must try to make breast feeding the norm in diabetic families.

Alberti mentions a possible link between consumption of bovine serum albumin and the development of insulin dependent diabetes. Karjalainen et al found raised antibodies to bovine serum albumin in most newly diagnosed insulin dependent diabetic patients. ${ }^{4}$ More importantly, Dahl-Jørgensen et al showed a close correlation between the amounts of cows' milk consumed per head of the population in various countries and the incidence of insulin dependent diabetes. ${ }^{5}$ This leaves little doubt that consumption of cows' milk is a trigger for diabetes mellitus. Bovine serum albumin is $97 \%$ denatured by ultraheat treatment of milk. We are assessing data to see whether ultraheat treated milk is less diabetogenic than pasteurised milk. 
We question whether children born to diabetic families should ever consume cows' milk. Breast milk and goats' milk are readily available in Britain, and their use should be encouraged for infants, children, and adolescents at risk of developing diabetes mellitus.

MR KIIN

Paxton Green Health Centre,

London SE21 8AU

DORA HENSCHEI

London SE13 7JD

LAURA KILN

Beckenham

Kent BR3 4JB

1 Alberti KGMM. Preventing insulin dependent diabetes mellitus. $B M 9$ 1993;307:1435-6. (4 December.)

2 Virtanen SM, Rasanen L, Aro A, Lindstrom, J, Tuomilehto J, Akerblom HK, et al. Infant feeding of Finnish diabetic children diagnosed before the age of 7 years compared to control children [abstract]. Diabetologia 1990;33:A197.

3 Borch-Johnsen K, Joner G, Mandrup-Poulsen T, Christy M Zachau-Christiansen B, Kastrup K, et al. Relationship between breast-feeding and incidence rates of insulin-dependen diabetes mellitus. Lancet 1984;ii: 1084-6.

4 Karjalainen J, Martin JM, Knip M, Ilonen J, Robinson BH, Savilahti E, et al. A bovine albumin peptide as a possible trigger of insulin dependent diabetes mellitus. $N$ Engl $f \mathrm{Med}$ 1992;327:302-7.

5 Dahl-Jørgensen K, Joner G, Hanssen KF. Relationship between cows' milk consumption and incidence of insulin dependent diabetes mellitus in childhood. Diabetes Care 1991;14:1081-3.

\section{Genetic prediction of adult onset disease}

EDrToR,-Genes for an increasing number of adult onset disorders are being defined, and in this era of budgetary restriction and planning by contract we wonder how long doctors can afford to ignore lessons learnt from predictive testing for Huntington's disease. After the localisation of the locus for Huntington's disease in $1983^{1}$ caution was initially exhibited by transatlantic colleagues, who wanted patients and their families legally to exonerate them from the consequences of giving bad news and from the predictable errors inherent in the use of linked genetic markers. In the United States and Britain extensive counselling programmes were developed. ${ }^{2}$ People could decide to be tested only after a period of reflection and after receiving accurate information about the limits of the test, the implications for other family members, and the problems of living with good and bad news.

The results of several hundred tests have now been given out in Britain, ${ }^{23}$ and the counselling programmes are accepted as the minimum for good practice in participating clinical genetics centres. This is in contrast to the situation in other centre in Europe and the United States, where appreciable problems have resulted when inadequate support was provided.

Counselling programmes may be expensive in clinical time, but follow up of the people who have had predictive testing for Huntington's disease in Britain has shown that over half are free of risk and its associated morbidity, while those who receive high risk results cope well with no appreciable changes to their lifestyle. ${ }^{5}$ These programmes save the NHS money as well as providing a good service for patients. People at high risk can be followed up so that their problems are dealt with promptly and they may benefit from current research into the disease. Patients find this reassuring, and some visit their general practitioner less frequently than before testing (personal communications from general practitioners).

To give predictive information about other incurable disorders of adult onset to asymptomatic people without such support may well be considered to be negligent. Genetics centres are receiving requests for predictive testing for motor neurone disease, Alzheimer's disease, and some cancers. We believe that clinicians must become aware urgently of the impact of the information that can be produced for these people and that these people should receive the benefit of the experience of the programmes concerned with Huntington's disease.

SHEILA A SIMPSON JOHN C S DEAN NEVA E HATTES

Department of Medical Genetics, Aberdeen Royal Inirmary, Aberdeen AB9 2ZB

1 Gusella JF, Wexler NS, Conneally PM, Naylor SL, Anderson $M A$, Tanzi RE, et al. A polymorphic marker genetically linked to Huntington's disease. Nature 1983;306:234-8.

2 Tyler A, Ball D, Crauford D, on behalf of the United Kingdom Huntington's Disease Prediction Consortium. Predictive testing for Huntington's disease in the United Kingdom. $B M F$ 1992;304:1593-6.

3 Simpson SA, Besson J, Alexander D, Allan K, Johnston AW. One hundred requests for predictive testing for Huntington's disease. Clin Genet 1992;41:326-30.

4 Simpson SA, Harding AE, on behalf of the United Kingdom Huntington's Disease Prediction Consortium. Predictive Huntington's Disease Prediction Consortium. Predictive 1993;30:1036-8.

5 Simpson SA, Besson J, Alexander D, Johnston AW. Huntington's disease in north east Scotland: predictive testing and sex ratio. Am 于 Hum Genet 1991;49(4) (suppl): 164 .

\section{Clusters of anophthalmia}

EDrToR,-Eduardo E Castilla states that the reported prevalence of anophthalmia and microphthalmia at birth in England and Wales $(0 \cdot 22 / 10000)$ is less than a quarter of the figure for the other populations for which the International Clearinghouse for Birth Defects Monitoring Systems receives data. ${ }^{1} \mathrm{He}$ also states that anophthalmia is the diagnosis in more than half the cases in England and Wales but in one quarter of those reported elsewhere.

The data for England and Wales come from the nationwide system centred on the Office of Population Censuses and Surveys, which covers only malformations notified soon after birth. In the experience of local English registries, which ascertain malformations from multiple sources, the prevalence of anophthalmia and microphthalmia at birth is much higher $(1 \cdot 3 / 10000$ in both Birmingham and Liverpool) and at least two thirds of affected subjects have only microphthalmia. ${ }^{23}$ These findings strongly suggest that the differences reported by Castilla are due (as he hinted that they might be) to incomplete ascertainment, especially of less severe cases, by the nationwide system for England and Wales. This and earlier evidence of the limitations of the nationwide system ${ }^{4}$ shows the need for caution when data from this source are used to explore possible clusters of malformations.

IAN LECK

Woodstock,

Oxford OX20 IUW

1 Castilla EE. Clusters of anophthalmia: No further clues from global investigation. $B M$ f 1994;308:206. (15 January.)

2 Leck I, Record RG, McKeown T, Edwards $\mathrm{JH}$. The incidence of malformations in Birmingham, England, 1950-1959. Teratology 1968;1:263-80.

3 EUROCAT Working Group. Surveillance of congenital anomalies 1980-1988. Brussels: Catholic University of Louvain, 1991. (EUROCAT report 4.)

4 Knox EG, Armstrong EH, Lancashire RJ. $f$ Epidemiol Community Health 1984;38:296-305.

\section{Tuberculous pericarditis}

EDrror,-The patient reported on by C P Clifford and $G J$ Davies, who had tuberculous pericarditis that rapidly progressed to constriction, was Sri Lankan.' Tuberculosis is the commonest cause of pericardial effusions in Sri Lanka. We recently prevented constrictive pericarditis in a boy in our unit by using steroids.
A 13 year old boy was admitted with fever and cough of two weeks' duration. He was febrile with a pulse of 96 beats/min and a jugular venous pressure of $5 \mathrm{~cm}$ water. He had a remarkable pericardial rub in the left sternal edge. A chest $x$ ray film showed severe cardiomegaly, and echocardiography confirmed a large periocardial effusion. A pericardial aspirate contained many red cells and lymphocytes but was repeatedly negative for acid fast bacilli. A Mantoux test yielded a negative result. He was given a course of antituberculosis treatment, and the fever settled completely in five days. Steroid treatment (prednisolone $10 \mathrm{mg}$ three times a day) was started one week after the start of antituberculosis treatment. An echocardiogram at one month showed a mild pericardial effusion with good contractility of ventricles and a normal ejection fraction.

A controlled clinical trial has shown that adding steroids increases the rate of recovery from tuberculous pericarditis compared with that with standard antituberculosis treatment alone. ${ }^{2}$ It also reduced the risk of death due to pericarditis and the need for pericardectomy. Furthermore, the highly potent antituberculosis regimen of streptomycin, rifampicin, isoniazid, and pyrazamide daily for 14 weeks followed by rifampicin and isoniazid for six months is believed to be associated with a lower death rate than the less potent regimen of rifampicin, isoniazid, ethambutol, and pyrazinamide for two months followed by rifampicin and isoniazid for four months. ${ }^{34}$

It is our practice to start steroids for all patients with tuberculous pericarditis only after the fever has responded to antituberculosis drugs. Thus antituberculosis drugs can be a diagnostic aid in pericardial effusions when the result of a Mantoux test is negative and acid fast bacilli cannot be isolated from pericardial fluid or sputum.

ANULA WIJESUNDERE S H SIRIBADDANA

Sri Jayewardenepura General Hospital,

Nugegoda,

Sri Lanka

1 Clifford CP, Davies GJ. Tuberculous pericarditis with rapid progression

Strang JG, Gibson DG, Nunn AJ, Kokaza HHS, Girlina DJ, Fox W. Controlled trial of prednisolone as adjuvant in treatment of tuberculous constrictive pericarditis in Transki. treatment of tuberculous

3 Haegman JH, Dlesopond, Glenn WWL. Tuberculous of the Haegman JH, Dlesopond, Glenn WWL. Tuberculous of the pericardium, a long ter
Med 1964;270:327-32.

4 Rooney J, Grocco JA, Lyons HA. Tuberculous pericarditis. Ann Intern Med 1970;72:73-8.

\section{Imaging methods used in acute aortic dissection}

EDrToR,-Our experience as radiologists in a large cardiothoracic centre does not lead us to support the imaging policy put forward by $\mathrm{C} M$ Francis and colleagues. ${ }^{1}$ Because aortic dissection requires rapid and accurate diagnosis since early surgery may be lifesaving ${ }^{2}$ we disagree with the suggestion that transoesophageal echocardiography is the best imaging method. The decision to intervene surgically and the type of operation depend on whether any part of the ascending aorta or vessels of the head and neck are affected. Francis and colleagues themselves state that transoesophageal echocardiography has a restricted view at this site, and it may result in an inaccurate diagnosis. This is supported by results of a study by Nienaber $e t a l$, which found a specificity of only $68 \%$ for transoesophageal echocardiography largely because of false positive findings in the ascending aorta. ${ }^{3}$ In addition, none of the useful information on aortic branch vessels, which are easily seen on angiography, can be obtained with transoesophageal echocardiography. We have also found 